\title{
The British National Food Survey as a major epidemiological resource
}

\author{
BRIAN J DERRY, DAVID H BUSS
}

In much of the work relating patterns of morbidity and mortality to diet the principal source of information about eating habits within Britain has been the National Food Survey conducted by the Ministry of Agriculture, Fisheries, and Food. Misunderstandings remain, however, about what this survey can and cannot show, and its use in epidemiological studies has sometimes been criticised. We therefore describe the survey, outlining its strengths and weaknesses for this purpose.

\section{History and objectives}

The National Food Survey is a continuous inquiry into the amounts and costs of food obtained by private households in Britain and of its nutrient content. The survey was begun in 1940 by the Ministry of Food to monitor the diets of urban working class families and thereby to provide an independent assessment of the effectiveness of wartime food policy. It became truly national in 1950 when it was extended to cover all sectors of the population, and since 1952 it has continued virtually unchanged. The National Food Survey therefore represents a unique source of information about British diets over more than 30 years. Though the emphasis of the survey has shifted somewhat from nutritional to economic uses in recent years, it continues to provide a regular flow of up to date information on the intakes of food and nutrients in Britain.

Ministry of Agriculture, Fisheries, and Food, London BRIAN J DERRY, BSC, FSs, head of National Food Survey branch DAVID H BUSS, PHD, head of nutrition branch

Correspondence to: Dr D H Buss, Ministry of Agriculture, Fisheries, and Food, Horseferry Road, London SWIP 2AE.

\section{Methodology and response}

The sample is selected at random to be representative of Britain as a whole. The sampling scheme has until now been based on parliamentary constituencies and electoral registers, ${ }^{1}$ but in 1984 a scheme based on local authority districts is to be introduced. The objective is to obtain an even coverage of Wales, Scotland, and each region of England and of rural, semirural, and urban areas within them. An even seasonal coverage is also obtained by spreading the interviews in the survey throughout each year.

Of the eligible households initially selected for the 1982 National Food Survey, 7945 (55\%) cooperated fully, equivalent to $65 \%$ of the households actually contacted (no replacement is permitted of households that could not be contacted). To clarify the implications of such a rate of response the characteristics of non-respondents to the 1971 survey were examined using their returns to the population census of the same year. ${ }^{2}$ The 1971 averages of total food expenditure from the National Food Survey were then reweighted to correct for the variations found in the response by different groups of households. This reweighting was found to make remarkably little difference to the national averages, suggesting that any bias caused by nonresponse is probably not serious.

\section{Method of recording and foods covered}

Households are recruited and helped in the survey by specially trained interviewers. The "housewife" (woman or man) is asked to keep a record for seven days of the description, quantity, and cost (if any) of all food items entering the home for human consumption. The only foods excluded are sweets, chocolates, and alcohol, which individual members of the household often buy for themselves without the housewife's knowledge; it is notoriously difficult for any survey to obtain accurate data on such items (though there is information on national supplies ${ }^{3}$ ). Free food is, however, included, whether obtained from an employer or from a garden or allotment (in the case of gardens or allotments, the amount consumed during the week of the survey is recorded, not the amount harvested). The housewife is also asked to note the members of the household and visitors present at each meal, together with a brief description of the 
foods served; this information is needed for the nutritional calculations described below.

Historically household food was classified by the survey into more than 150 standard categories, but some of these have been further subdivided in recent years so that in 1983 over 200 separate foods are being distinguished. These range from such narrow, well defined categories such as standard, large, white, sliced loaves of bread to less homogeneous groupings such as frozen cereal convenience foods. Averages of the quantities "consumed" (defined as the sum of purchases and free food) for each category are calculated, as are the amounts spent per person per week and the average prices paid. National results are produced for individual months, quarters, and years, enabling trends in consumption to be monitored over time, as in the example given in the figure.

Quarterly and annual averages are also calculated separately for groups of households classified according to various alternative criteria, including region, composition of family, and income; results can also be produced by social class, parliamentary constituency, and according to certain other characteristics. The table gives an example of geographical variations in the average consumption of selected foods from 1975 to $1980^{4}$; such differences are remarkably stable over time.

\section{Nutritional estimates}

The recorded amounts of food are also expressed in terms of their component nutrients using factors based on standard food tables. ${ }^{5}$ These factors allow for inedible material-for example, meat bones and vegetable skins-but not for household wastage. In this way estimates are obtained of nutrient intakes, both at the national level

Geographical variations in household consumption of selected foods (percentage deviations from national averages, 1975-80)

\begin{tabular}{lrrrc}
\hline & Scotland & Wales & England & Greater London \\
\hline Milk & 0 & -2 & 0 & -4 \\
Cheese & -7 & -10 & +1 & +6 \\
Beef & +40 & -21 & -2 & +4 \\
Lamb & -53 & +10 & +5 & +43 \\
Pork & -51 & -7 & +6 & +28 \\
Fish & -7 & -6 & +1 & -11 \\
Eggs & +8 & -5 & -1 & -1 \\
Butter & -4 & -6 & +1 & -29 \\
Margarine & -4 & +5 & 0 & -13 \\
Sugar & +8 & +18 & -2 & -5 \\
Potatoes & -50 & 0 & +5 & +11 \\
Fresh green & -19 & -5 & +2 & +25 \\
vegetables & +11 & -2 & -10 \\
Fresh fruit & -15 & +13 & 0 & +3 \\
Bread & -11 & -23 & +2 & +2 \\
Tea & -20 & & & \\
\hline
\end{tabular}

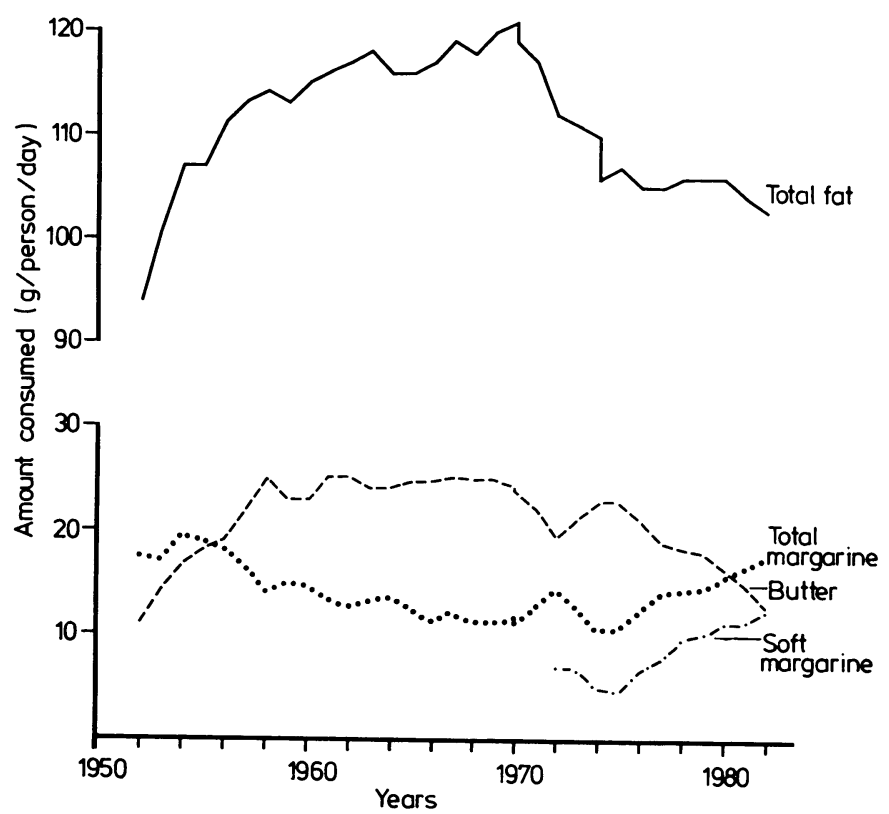

Trends in household consumption of butter, margarine, and total fat in Britain from 1952 to 1982 . and for the various groups of households described above. As an example, the figure shows the trend in total fat intake from 1952 to 1982.

Variations between different groups of households can be difficult to interpret because they may have different nutritional needs-for example, families with small children generally have lesser requirements per head than those with adults only. Moreover, households that eat out relatively often will generally obtain less food for consumption in the home. In an attempt to allow for such factors, the average intakes from the National Food Survey are also compared with the recommendations by the Department of Health and Social Security for groups of people. ${ }^{6}$ As the DHSS recommendations refer to nutrients obtained from all sources some adjustments are necessary before these particular comparisons may be made. Thus, for this purpose only, the estimated intakes are first reduced by $10 \%$ to allow for wastage of edible food. This standard deduction is somewhat higher than recorded by some surveys, ${ }^{7}$ but most errors of recording on the difficult topic of food wastage are omissions: not all food can be scraped from cooking vessels, all spillage collected, or every scrap salvaged from the jaws of pets.

The recommendations of the DHSS must also be adjusted to allow for the needs of those members of the household that were met outside the home and for those of visitors who were fed from the food supply of the household. This entails an assessment of the weighted proportion of every person's meals (dinner is assumed to have a greater nutritional importance than breakfast, for example) that were taken at home. It is then assumed that an equivalent proportion of their nutritional needs would be met from the food supply of the household, and the recommendations of the DHSS are scaled down accordingly. In this way the intakes of the National Food Survey and the recommendations of the DHSS are reduced to a comparable basis, the main exception being the exclusion of sweets, soft drinks, and alcohol from the National Food Survey.

\section{Availability of results}

Full details of the findings and methodology of the survey are published in annual reports, the latest being for $1981 .{ }^{8}$ Quarterly results, however, are available much more quickly, and these and other unpublished results and special analyses can be provided on payment of a fee. In addition, the basic survey data of food acquisitions -but not of nutrient intakes-for 1979 and 1980 are currently available on computer tape from the Economic and Social Research Council's data archive at the University of Essex, and results for subsequent years will be deposited there in due course.

\section{Strengths and limitations of the survey}

The principal limitations of the National Food Survey from a nutritional and epidemiological standpoint are essentially fivefold.

(1) It is confined to food brought home. It has been estimated, however, that such food generally represents at least $85-90 \%$ of the total eaten, and the patterns of meals at home and outside have been found to be similar. ${ }^{9}$ Moreover, when intakes of nutrients are compared with the recommendations of the DHSS, allowance is made for the contributions made by meals out. This practice is considered to provide a better assessment of trends over time and of the relative positions of different groups of households.

(2) It excludes sweets, alcohol, soft drinks, and vitamin pills. Apart from vitamin pills these are essentially only sources of energy. If, through sheer lack of food, involuntary energy deficiency were ever a problem, it should be readily apparent from medical or other evidence long before it would be unequivocally shown by any nutritional survey. Arguably, therefore, the regular monitoring of trends in vitamin and mineral intakes is a more immediately useful nutritional function.

(3) It records acquisitions of food rather than amounts actually eaten. If, however, the recorded amounts of purchased and free food are averaged over a sufficient time or a large number of households, they should represent-waste apartwhat is actually eaten by such households, provided that there is no systematic change in their general level of food stocks.

(4) The nutrient content of household food is estimated using 
average factors from standard food tables rather than by direct chemical analysis of the specific items concerned. The same is true, however, for almost all nutritional surveys.

(5) As a result of limitations (3) and (4), and because each family takes part in the survey for only seven days, the National Food Survey can say nothing about the nutrient intake or eating behaviour of individual household members or indeed of individual households. It can only reasonably provide estimates for fairly broad groups of households; but the recommendations of the DHSS are framed in similar terms. Furthermore, the food consumption of any family or individual during a single week, no matter how accurately measured, is unlikely to be directly reflected in their later morbidity or mortality. Epidemiological studies are therefore usually concerned with group averages.

The main strength of the National Food Survey is that it provides continuous information on food and nutrient intakes now spanning more than 30 years, not only for Britain as a whole but also for many subgroups within the population. Though constrained by financial and practical considerations, it remains an up to date, readily accessible, and comparatively cheap means of monitoring trends in household food consumption and of assessing a major aspect of nutritional state for epidemiologists to compare with any similar temporal or cross sectional data on morbidity and mortality.

\section{References}

1 Ministry of Agriculture, Fisheries and Food. Household food consumption and expenditure: 1981. Appendix A. London: HMSO, 1983.

${ }^{2}$ Kemsley WFF. Statistical news. No 35. London: HMSO, 1976.

${ }^{3}$ Ministry of Agriculture, Fisheries and Food. Estimates of food and drink supplies moving into human consumption. British Business 1983;12:557.

4 Ministry of Agriculture, Fisheries and Food. Household food consumption and expenditure: 1980. Based on Table 14. London: HMSO, 1982.

5 Paul AA, Southgate DAT. McCance and Widdowson's the composition of foods. 4th ed. London: HMSO, 1978.

- Department of Health and Social Security. Recommended daily amounts of food energy and nutrients for groups of people in the United Kingdom. London: HMSO, 1979. (Reports on Health and Social Subjects; No 15.)

7 Wenlock RW, Buss DH, Derry BJ, Dixon EJ. Household food wastage in Britain. Br $\mathcal{F}$ Nutr 1980;43:53-70.

${ }^{8}$ Ministry of Agriculture, Fisheries and Food. Household food consumption and expenditure: 1981. London: HMSO, 1983.

2 Hughes ML. Regional food preferences. Guildford: University of Surrey, 1976. 410 pp. Thesis.

(Accepted 15 November 1983)

\title{
Necessary safeguards when prescribing opioid drugs to addicts: experience of drug dependence clinics in London
}

\author{
P H CONNELL, M MITCHESON
}

The management and treatment of opiate addiction comprise a range of different approaches. Although not the most important element of treatment, prescribing a reducing or maintenance dose of drugs may be highly controversial and is undoubtedly a decision which should not be taken lightly or before careful review of the individual patient. We describe safeguards based on procedures that have been developed by the special drug dependence clinics in London over 15 years and been generally agreed in mutual discussion.

\section{Background}

The growing problem of heroin abuse by young adults during the 1960 s led to the setting up of special clinics for the treatment of drug dependence. The approach at that time included the concept outlined in the United Kingdom by the Rolleston committee in 1926 that it was reasonable medical practice to maintain patients with a regular dose of prescribed opioids, who would then be stable and able to lead a normal and useful life. ${ }^{1}$ This practice was first set out as a response to middle aged and elderly patients who had become dependent on drugs in the course of medical treatment. The pre-

Drug Dependence Clinical Research and Treatment Unit, The Maudsley Hospital, London SE5 8AZ

P H CONNELL, FRCP, FRCPSYCH, director

Drug Dependence Clinic, University College Hospital, London WC1E 6AU

M MITCHESON, MRCPSYCH, DPM, consultant in charge

Correspondence to: Dr P H Connell, 21 Wimpole Street, London WIM 7AD. scribing of large amounts of heroin to the younger drug taker of the 1960 s by a limited number of independent practitioners was identified by the second Brain committee as contributing to the oversupply of drugs. ${ }^{2}$ In order to control the supply-but without cutting off legal supplies altogether-the committee modified the previous practice in part by recommending the restriction of the power to prescribe heroin and cocaine for addicts to doctors in receipt of a special licence. The shift in tone and content from the earlier Rolleston to the Brain committee reports suggested a change of emphasis from helping an individual to continue in a stable and socially productive lifestyle to one of controlling the supply of drugs and restricting the criminal activity associated with drug use. In the same period the United States was moving from a strictly law enforcement attitude which included compulsory hospital treatment to maintenance with oral methadone in special clinics for the management and treatment of heroin addicts. Maintenance treatment with this drug was later controlled under federal and state legislation.

When the clinics were set up in 1968 to implement the Brain committee recommendations there was little knowledge or experience among consultants, junior doctors, or other staff to help them. Most clinics were in London, the major area of heroin availability and addiction. The Department of Health convened regular meetings of the staff of these clinics, where information was shared regarding policies and experience. These meetings have continued in various forms, the clinics taking over the responsibility for organisation. It has never been possible to obtain agreement that might result in the imposition of a uniform clinical approach with formal agreed procedures for the management of all patients; nor, indeed, in the view of the majority of members, is this even desirable. There has, however, been substantial agreement on styles of treatment and it has been possible to ensure that for almost anyone living within the boundaries of Greater London (with the exception of two or three boroughs) a clinic has been identified which will accept responsibility for providing a service; much valuable information has been shared regarding changes in the favoured substance of abuse, new fads, and dangerous side effects. Nevertheless, each consultant operates as an independent doctor, with the right to treat patients as 